\title{
A Fallacy Analysis of the Arguments on the First U.S. Presidential Debate Between Hillary Clinton and Donald Trump
}

\author{
Jennifer Marella Santoso \\ English Department, Faculty of Letters, Petra Christian University \\ Surabaya, East Java, Indonesia \\ E-mail: marella_js@ymail.com
}

\begin{abstract}
This research studies the fallacy in the arguments on the first 2016 U.S. presidential debate between Hillary Clinton and Donald Trump. This research is aimed to find out the fallacies occurred in the debate, the dominant fallacy made by each candidate, and the similarities and differences in each candidate's fallacy. The topic on fallacy is chosen because fallacies are persuasive, yet misleading arguments which might contribute on influencing the people's vote. In analyzing the data, the writer used the theory of arguments by Bierman and Assali (1996) and the theory of fallacy by Inch and Warnick (2011). From the total of 22 arguments, four of which are sound arguments. There is a total of 25 fallacies falling into six types which occurred. The most frequently occurred fallacy type is the "straw person" while the "audience-based" category becomes the dominant fallacy category. Furthermore, the writer found that Clinton made all of the sound arguments while Trump made all of the "hasty generalization" and the "ad populum" fallacy.
\end{abstract}

Keywords: Debate, Fallacy, Argument

A presidential election determines the direction of a nation in the future, including the United States of America which had its $58^{\text {th }}$ quadrennial presidential election in November 2016. After going through some primaries, America finally had its two presidential candidates from the two major parties, Donald Trump from the Republican Party and Hillary Clinton from the Democratic Party. While Clinton is the first female president candidate from a major political party and has a background in politics, Trump came as an interesting figure since his background is from business, rather than politics.

To win and convince the audience that the candidate is the right person to lead America, having a strong argument is very important. However, in reality, people often make "fallacy" which is a false argument that may seem reasonable and acceptable, but is based on erroneous assumptions or invalid reasoning (Inch and Warnick, 2011). The problem is that fallacies can be persuasive and lead people to misconceptions or misunderstandings. Furthermore, committing a fallacy can be either unintentional or intentional. In other words, it can be created subconsciously by mistake or deliberately with the purpose of manipulating the debate. That is why, although it's erroneous, fallacies might still being deliberately used by the candidates to achieve their purpose in winning the audience which intrigues the writer to analyze fallacy despite other different approaches.

Both candidates have done various campaign methods. However, the writer chose the presidential debate as the most interesting subject to analyze, because debates have greater viewership than any other campaign messages (Rieke, Sillars, and Peterson, 2005). The debate would also give the audience a better opportunity to compare the candidates (Freeley and Steinberg, 2009). The writer choose the first out of the three debates since the first debate is the most-viewed U.S. presidential debate ever. The format of the debate is divided into six 15 minutes segments focusing on major topics. Each segment began with a question which each candidate has two minutes to respond and continued with a 10 minute of open debate and discussion. This research focuses on the topic of "Achieving Prosperity" which happens on the first 30 minutes of the debate and talks about the economy. In addition, the writer limited this research to Hillary Clinton's and Donald Trump's arguments which are related to the economy.

Before the election took place, many prominent news sites deemed Clinton as the winner for the 
presidential debates. She also won the popular vote by almost 3 million votes (Krieg, 2016). However, the result of the presidential election spoke differently as Trump won the election race through the Electoral College. Although there may or may not be a relation between the arguments presented in the debate and the candidates' winning and losing position, the writer will not discuss the possibilities as there are a lot more aspects which affect the result, such as political influence and the candidates' image to the public. Therefore, the writer will only focus on analyzing the linguistic aspects of the debate.

Through this research, the writer wants to find out the fallacies as well as the dominant type of fallacy in the arguments stated by Hillary Clinton and Donald Trump in their first presidential debate. Furthermore, from fallacies that are found, the writer wanted to discover the similarities and differences in the fallacies made by both candidates.

To provide answers to the research questions, the writer used the theory of argument by Bierman and Assali (1996) and the theory on fallacy by Inch and Warnick (2011). An argument is defined as "a sequence of statements in which statements, called premises, are given as reasons or evidence for the truth of a statement, called conclusion" (Bierman and Assali, 1996, p.33). In other words, an argument must provide some reasons for believing that the conclusion is true. If a set of statements does not contain both premise and conclusion, it cannot be classified as an argument. However, in reality, one would not want explicitly to state all of one's premises, for that would belabor the point and bore the audience (Inch and Warnick, 2011). This makes most arguments elliptical which means the argument is presented with either a missing premise or conclusion. Premises or conclusions that are required for validity are left out, since the arguer considers it too obvious to be stated. Therefore, the audience need to supply the argument with their own assumptions.

In everyday life, people often make an argument that is flawed by irrelevant or inadequate evidence, erroneous reasoning, or improper expression called "fallacy" (Inch and Warnick, 2011, p.242). In other words, fallacy represents a misuse of argument which resulted in confusing or incorrect arguments. However, although incorrect, fallacies can deceive the audience due to its persuasive nature. Inch and Warnick (2011) have classified fallacies into four groups. First is "audience based" fallacies which aim is to direct the audience's attention away from the central argument to some other irrelevant argument. This group is made up of four fallacies. "Ad hominem", a common fallacy in political debates, is an irrelevant attack on a person's character or behavior to discredit their arguments or views. " $A d$ populum" happens when the argument's claim is based on popular beliefs and opinions instead of on reason and evidence. "Appeal to Tradition" occurs when the argument turns convention into a reason for not making a change. Lastly, "Straw Person", another common fallacy in political debates, occurs when someone's argument is deliberately misinterpreted or exaggerated. The arguer creates a weakened version of an argument through distortion and then attacks their own creation.

The next group is "language use" fallacies which occur when words and grammar used by the arguer mislead or confused the audience. It consists of three fallacies. "Equivocation" uses doublemeaning words to arrive at a false conclusion while "Amphiboly" happens when there is an ambiguity in grammatical structure. "Emotive Language" occurs when the arguer uses connotative meaning of words to persuade the audience emotionally.

After that, there are "grounding" fallacies which stem from the lack, poor quality, or incorrect use of evidence. This group consists of "Begging the Question" which happens when the idea of the argument's conclusion is the same as the premises, and "Non Sequitur" which uses illogical premises that fail to support the conclusion.

Lastly is the "reasoning" fallacies which come from a faulty reasoning that provide incorrect or insufficient connection between the evidence and the claim. There are four fallacies under this group. The "False Analogy" fallacy compares two things that are not alike. "Hasty Generalization" is found when the arguer draws a conclusion about a class based on too few or atypical examples example. "False Cause" occurs when a sequential relationship is mistaken for a causal relationship. Finally, the "Slippery Slope" fallacy happens when one assumes, without evidence, that an action will lead to, through a series of connections, an inevitable outcome. 


\section{METHODS}

The writer used a descriptive quantitative research approach in doing the analysis since she used numbers in discussing her findings. The use of numbers supports the writer in finding the dominant fallacy as well as the similarities and differences in both candidates' fallacy. The transcript of the first presidential debate between Hillary Clinton and Donald Trump on the topic of "Achieving Prosperity" became the source of data. The topic was chosen because in addition to being the longest, that part also covered one of the general categories of political argumentation which is finance (Rieke, Sillars, and Peterson, 2005). Furthermore, a poll by Gallup also stated that 33\% of Americans believe that economy is the most important issue to be discussed. Thus, the data of this study is the arguments related to the topic of economy which was made by both presidential candidates.

In collecting the data, first of all the writer searched the debate's video and transcript. Then, she watched the debate while reading the transcription to understand the issues raised as well as its overview better. Next, the writer calculated the length of each topic and segment by counting the video duration to limit the analysis and make it more focused. After that, the writer identified and collected the arguments from the transcript and marked the arguments by underlying them. To identify the arguments, the writer needed to understand the overall idea of the argument and find out whether the utterances have a sequence of premises and conclusion. If it lacked either a premise or conclusion, the writer will not classified it as an argument. However, in the time given for each candidate to propose their arguments, often times both candidates presented several arguments. Therefore, to divide one argument from another, the writer used Inch and Warnick's (2011) steps for argument analysis. The process began with figuring out what the arguer means. The writer needed to understand the definition and the points which the candidates were trying to convey. The second step is to number the statements in the argument. The next step is to find the conclusion of the argument. If there is more than one main claim or conclusion, it means there is more than one argument. In other words, the writer will use the changing of topic sentence for separating and marking the unit of analysis. The fourth step is to diagram the argument. For this step, the writer used Bierman and Assali's (1996) procedure for diagramming arguments which will be explained in the next paragraph. Lastly, the argument is criticized. In this step, the writer analyze the argument and find whether it contains fallacy or not.

To make it easier to analyze the argument, the writer reconstructed the arguments using Bierman and Assali's (1996) procedure for diagramming arguments. First of all, the writer separated each proposition in the argument by bracketing and numbering. In this process, some sentences will be broken up and given more than one number if they contained more than one claim. Additional claims which did not act as either premise or conclusion will not be bracketed or numbered. Furthermore, if a claim was mentioned twice or more in an argument, the writer would give the same number to the claims. After that, the writer made the index of claims. In the index of claims, the claims were reduced and separated into simpler forms by eliminating unimportant words or paraphrasing the claim. After separating the claims, the writer identified the argument's conclusion by underlining. In some cases, the writer will supply additional claims to the index which act as either a missing premise or conclusion in elliptical arguments. This is done to make the argument clearer and easier to understand. To differentiate the additional claim with the other claims, the additional claim will be stated in the index using brackets and alphabets instead of numbers.

In analyzing the data, the arguments were compiled into a table so the writer could analyze and identify which fallacy it fall into. The table was also used to count the frequency and percentage for each type.

\section{FINDINGS AND DISCUSSION}

The writer found that certain fallacies did not occur throughout the debate. There are only six fallacies which occurred: straw person, ad hominem, hasty generalization, false cause, slippery slope, and ad populum. The "straw person" becomes the most frequently occurred fallacy and followed by "ad hominem". In committing the straw person fallacy, the arguer changes the truth of the argument in order 
to suit the arguer's own needs (Ramage, Bean, \& Johnson, 2004). The arguer basically make up the argument they wish their opponents had made and attack their creation by themselves. Below is an example of straw person fallacy in Trump's argument:

1[Let me give you the example of Mexico. They have a VAT tax.] 2[We're on a different system. When we sell into Mexico, there's a tax. / When they sell in -- automatic, 16 percent, approximately. 1/When they sell into us, there's no tax.] 3[It's a defective agreement. It's been defective for a long time, many years, but the politicians haven't done anything about it.l

Index of claims:

1. Mexico have VAT tax system in which when Mexico sell their product to us, there's no tax

2. When we sell our product to Mexico, there's a tax.

(A. America suffer a financial loss in trading with Mexico)

3. It's a defective agreement, but the politicians haven't done anything about it

In the argument above, the difference in taxing system becomes the main issue. Value Added Tax (VAT) is a type of consumption tax that is paid by the customers when they buy a product or a service. Trump argued that America suffers a financial loss when trading with Mexico because Mexico is under VAT system while America is not. Trump intends to say that America has a disadvantage agreement that needs to be terminated or changed. However, VAT has a border adjustable system which makes the tax burdens from the exporter country to not be transported to the importer country when exporting goods. Therefore, it won't cause double tax burden on either country. Therefore, Trump creates a misleading argument on the VAT system and proceeds to attack his own creation by calling it "a defective agreement".

Following the "straw person", "ad hominem" which is the second most occurring fallacy focuses on attacking the character of the person making the argument than the quality of the reasoning (Ramage, Bean, \& Johnson, 2004). This fallacy shifts the audience's attention from the important issue to the irrelevant flaws of the opponent's character or behavior. An example of this fallacy is found in Clinton's argument:

So you've got to ask yourself, 1[why won't he release his tax returns? And I think there may be a couple of reasons.] 2[First, maybe he's not as rich as he says he is.] 3/Second, maybe he's not as charitable as he claims to be.] 4[Third, we don't know all of his business dealings, but we have been told through investigative reporting that he owes about $\$ 650$ million to Wall Street and foreign banks.7 Or 5/maybe he doesn't want the American people, all of you watching tonight, to know that he's paid nothing in federal taxes, I because 6/the only years that anybody's ever seen were a couple of years when he had to turn them over to state authorities when he was trying to get a casino license, and they showed he didn't pay any federal income tax.] 7/So if he's paid zero, that means zero for troops, zero for vets, zero for schools or health.] And 8[I think probably he's not all that enthusiastic about having the rest of our country see what the real reasons arel, because 9/it must be something really important, even terrible, that he's trying to hide.l

Index of claims:

1. I think there may be a couple of reasons for why he won't release his tax returns

2. First, maybe he's not as rich as he says he is

3. Second, maybe he's not as charitable as he claims to be.

4. Third, we don't know all of his business dealings, but we have been told through investigative reporting that he owes about $\$ 650$ million to Wall Street and foreign banks

5. Maybe he doesn't want the American people to know that he's paid nothing in federal taxes,

6. The only years that anybody's ever seen him paid taxes were a couple of years when he had to turn them over to state authorities when he was trying to get a casino license, and they showed he didn't pay any federal income tax

7. If he's paid zero tax, that means zero for troops, zero for vets, zero for schools or health 
8. I think probably he's not all that enthusiastic about having the rest of our country see what the real reasons are

9. It must be something really important, even terrible, that he's trying to hide.

In this argument, Clinton talked about Trump's possible reasons for not releasing his tax returns. Information on a candidate's tax returns is important because it gives the voters the knowledge of the taxable income the candidate made, the amount of taxes the candidate has paid, and the candidate's charity donations (Jacobson, 2016). However, the Internal Revenue Service (IRS) said that there was no prohibition to release the tax returns during an audit. Clinton tries to discredit Trump's reputation by launching attacks on his personal character. She wants to say that Trump is a liar and an irresponsible person.

The writer identified 22 arguments in total. From the 22 arguments, 11 is made by Clinton, and the other 11 is made by Trump. Four of Clinton's arguments are sound arguments while all of Trump's arguments are fallacious. Furthermore, the writer found that Clinton made 9 fallacies in her arguments while Trump produced 16 fallacies. The following table is the result of the types of fallacy each candidate made.

Table 1. Frequency of Types of Fallacy made by Clinton and Trump

\begin{tabular}{|l|c|c|c|c|}
\hline \multirow{2}{*}{\multicolumn{1}{|c|}{ Fallacy }} & \multicolumn{2}{c|}{ Clinton } & \multicolumn{2}{c|}{ Trump } \\
\cline { 2 - 5 } & $\begin{array}{c}\text { Number of } \\
\text { Fallacious } \\
\text { Arguments }\end{array}$ & Percentage & $\begin{array}{c}\text { Number of } \\
\text { Fallacious } \\
\text { Arguments }\end{array}$ & Percentage \\
\hline Ad Hominem & 2 & $22.22 \%$ & 3 & $18.75 \%$ \\
\hline Ad Populum & 0 & 0 & 1 & $6.25 \%$ \\
\hline Appeal to Tradition & 0 & 0 & 0 & 0 \\
\hline Straw Person & 4 & $44.44 \%$ & 7 & $43.75 \%$ \\
\hline Equivocation & 0 & 0 & 0 & 0 \\
\hline Amphiboly & 0 & 0 & 0 & 0 \\
\hline Emotive Language & 0 & 0 & 0 & 0 \\
\hline Begging the Question & 0 & 0 & 0 & 0 \\
\hline Non Sequitur & 0 & 0 & 0 & 0 \\
\hline False Analogy & 0 & 0 & 0 & 0 \\
\hline Hasty Generalization & 0 & 0 & 3 & $18.75 \%$ \\
\hline False Cause & 2 & $22.22 \%$ & 1 & $6.25 \%$ \\
\hline Slippery Slope & 1 & $11.11 \%$ & 1 & $6.25 \%$ \\
\hline
\end{tabular}

The table above reveals that the dominant type of fallacy made by both candidates is the same which is "straw person". According to Inch and Warnick (2011), the arguer advances a "straw person" argument to bolster the arguer's own position. The "straw person" fallacy itself falls in the audiencebased category which characteristic is to misdirect the audience's attention. Therefore, it can be said that the candidates are trying to make their arguments and position appear better than their opponent so that the Americans will be persuaded to vote for them. However, they do it by advancing a false argument to make the audience favor them. The differences, on the other hand, lie in the number of sound and fallacious arguments as well as the kinds of fallacies they make.

From the findings, there are several things that we can pay attention to. Firstly, both Trump and Clinton committed the "straw person" fallacy the most in the debate. It is possible because both candidates find it easier to make a false argument and attack it than responding to the actual argument. Secondly, although fallacy is prevalent, there are certain kinds of fallacy that more frequently occurring than the rest in the debate which are the "straw person" and "ad hominem", both falls in the category of audience-based fallacy. This might be because of the nature of the interaction which is a political debate. Both candidates try to twist the arguments and attack the characters to boost their own election rate or 
shift the focus of the debate.

According to Rieke. Sillars, and Peterson (2005), argumentation in political campaigns is image centered since it contains the question whether the candidate is a suitable representative to be elected. This can be seen in the use of "ad hominem" fallacy to attack a candidate's image, or the use of "ad populum" and "false cause" to increase their credibility. Aside from image, campaign arguments are also linked to the people. The candidates need to be seen as a leader who acts in people's best interest while the opponent as someone harmful to the people This can be seen from some "straw person" fallacies that are used to weaken the opponent's argument, such as when Clinton claims that Trump's plan will not cause repatriation and when Trump claims Clinton's tax plan will drive business out.

Thirdly, there is no fallacies from the "language use" category found in any of the arguments. One of the possible reason is because both candidates realize that it is better to use straightforward words and easy grammatical structures to make the audience understand their arguments better. There is also no fallacies from the "grounding" category. One of the reasons might be because both candidates realize that it would be better to use logical evidence to win the audience.

Lastly, the writer notes the difference on fallacy between Clinton and Trump. Clinton did not commit the "hasty generalization" and "ad populum" fallacy while Trump did not make any sound arguments. The writer attributes this to each candidate's personality. According to Personality Pathways, one of Clinton's strengths rely on her doing things methodically and carefully, possibly including in bringing her arguments up. This might be why she made all of the sound arguments and did not jump to conclusions. Trump, on the other hand, is spontaneous and an action-oriented person (Reinhold, 2016). He tends to like public events and arguing with people. This makes him more inclined to talk in the heat of the moment; thus making him more prone to make fallacies and come to hasty conclusion.

\section{CONCLUSION}

In this research, the writer observed the fallacies which occurred in the arguments in the first U.S. presidential debate between Hillary Clinton and Donald Trump. Through this research, the writer wanted to know the kinds of fallacy made by both candidates as well as the similarities and differences. There are two theories used for doing the analysis which are the theory on arguments by Bierman and Assali (1996) and the theory on fallacy by Inch and Warnick (2011).

From the result of the analysis, it can be concluded that fallacy is prevalent in debates. Out of the twenty two arguments identified in the first part of the first presidential debate, only four of them are sound arguments. The result also shows that, out of the thirteen fallacies used in the theory, there are only six fallacies which occurred in the debate. They are straw person, ad hominem, hasty generalization, false cause, slippery slope, and ad populum.

The writer found that, in terms of fallacy type, both candidates made the "straw person" fallacy the most. This might be done to make their arguments and position appear better than their opponent or shift the focus of the topic. On the other hand, in terms of fallacy category, the "audience-based" becomes the dominant category. One of the possible reason is because the format of the event is a political debate in which both candidates mostly try to twist the arguments and attack the characters to increase their election rate. Furthermore, arguments in political campaigns involves issues and images since it deals with whether the candidate is a suitable representative to be elected. The use of "ad hominem" fallacy to attack a candidate's image as well as the use of "ad populum" and "false cause" to increase their credibility are evidence to this point. Aside from image, campaign arguments are also linked to the people. The candidates need to be seen as someone supportive while the opponent as someone harmful to the people. One way is by using "straw person" to advance a false argument on the opponent.

The writer also found that there are some fallacies which do not occur throughout the debate, such as "equivocation" and "amphiboly" which falls in the "language use" category. One of the possible reason for this is that both candidates realize it is better not to confuse the audience using ambiguous words and structure to win their support. There is also no fallacy from the "grounding" category which occurred. This might be because both candidates think this is not an effective way to win the audience's vote. Another interesting point is that Clinton made all four of the sound arguments while all of Trump's 
arguments are fallacious. The writer links this to each candidate's personality. Their personality is also attributed as to why Trump made some fallacies which Clinton does not commit which are "hasty generalization" and "ad populum".

In the end, the writer hopes that this research can contribute to the field of logic and critical thinking, especially in the study of argumentation. This research is conducted in a small scale which focused on one topic, the economy, and certain kinds of fallacies. Therefore, the writer encourages future researcher to conduct further studies about fallacies, for instance by comparing the fallacies made between different topics and interactions.

\section{REFERENCES}

Bierman, A. K., \& Assali, R. N. (1996). The critical thinking handbook. New Jersey: Prentice Hall.

Freeley, A. J., \& Steinberg, D. L. (2009). Argumentation and debate: critical thinking for reasoned decision making (12 ${ }^{\text {th }}$ ed.). Boston: Wadsworth Cengage Learning.

Gallup. (n.d.). Most important problem. Retrieved February 18, 2017, from Gallup: http://www.gallup.com/poll/1675/most-important-problem.aspx

Inch, E. S., \& Warnick, B. (2011). Critical thinking and communication: the use of reason in argument $\left(6^{\text {th }}\right.$ ed.). Boston: Pearson.

Jacobson, L. (2016, September 26). Donald Trump wrong that 'you will learn more' from financial disclosure form than from tax returns. Retrieved from Politifact:

http://www.politifact.com/truth-o-meter/statements/2016/sep/26/donald-trump/donald-trumptalks-about-his-finances-first-presid/

Krieg, G. (2016, December 22). It's official: Clinton swamps Trump in popular vote. Retrieved March 29, 2017, from CNN Politics: http://edition.cnn.com/2016/12/21/politics/donald-trump-hillaryclinton-popular-vote-final-count/

Ramage, J. D., Bean, J. C., \& Johnson, J. (2004). Writing arguments: a rhetoric with readings $\left(6^{\text {th }}\right.$ ed.). United States of America: Pearson Education.

Reinhold, R. (2016, September). Donald Trump ESTP Hillary Clinton INTJ - leadership styles. Retrieved from Personality Pathways: http://www.personalitypathways.com/article/trumpclinton-mbti-type.html

Rieke, R. D., Sillars, M. O., \& Peterson, T. R. (2005). Argumentation and critical decision making (6th ed.). United States of America: Person Education. 